
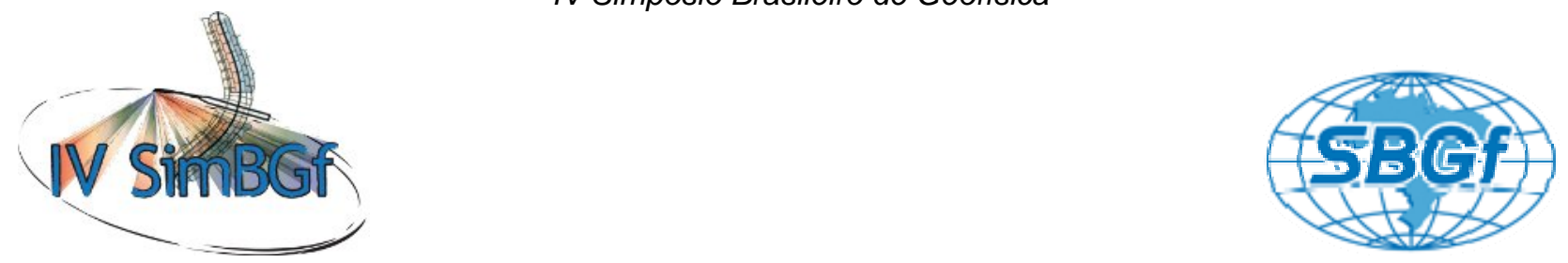

\title{
Magnetometria, Gamaespectrometria e Gravimetria da Região de Junção dos Terrenos Alto Moxotó, Rio Capibaribe e Pernambuco-Alagoas da Província Borborema

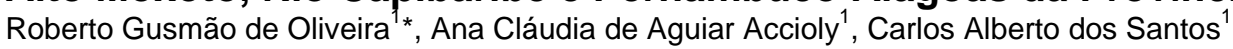
1- CPRM - Serviço Geológico do Brasil

Copyright 2010, SBGf - Sociedade Brasileira de Geofísica

Este texto foi preparado para a apresentação no IV Simpósio Brasileiro de Geofísica, Brasília, 14 a 17 de novembro de 2010. Seu conteúdo foi revisado pelo Comitê Técnico do IV SimBGf, mas não necessariamente representa a opinião da SBGf ou de seus associados. É proibida a reprodução total ou parcial deste material para propósitos comerciais sem prévia autorização da SBGf.

\section{Abstract}

This paper describes the correlation between geological and geophysical data for the region of the junction of three geological domains, Alto Moxotó, Rio Capibaribe and Pernambuco - Alagoas, interpreted as tectonostratigraphic terranes, and located in the Borborema Province. The interpretation of data strengthened the geological model of the juxtaposition of diverse crusts with petrophysical properties, bounded by Congo - Cruzeiro do Nordeste and Pernambuco shear zones. The correlation showed remarkable contrasts of density, magnetism and radioactivity among the three geological domains. In the analysis of gravity data in a collision model, the Congo - Cruzeiro do Nordeste shear zone would be the candidate most likely to mark a suture zone.
\end{abstract}

\section{Introdução}

Nos últimos anos tem ocorrido um debate intenso sobre os modelos geológicos mais adequados que possam explicar a complexidade geológica observada na Província Borborema. Entre esses modelos, destaca-se a proposta de que a província foi formada ao longo do tempo pela junção de grandes fragmentos de crostas (terrenos), atualmente justapostos ao longo das zonas de cisalhamentos (Jardim de Sá et al., 1992; Santos, 1996). Neste trabalho foi escolhida uma área chave para discussão da validade deste modelo com o emprego de dados geofísicos. Esta área está localizada na junção de três diferentes terrenos propostos por Santos (2000): Alto Moxotó, Rio Capibaribe e Pernambuco - Alagoas (Figura 1).

\section{Contexto Geológico}

A área de estudo está localizada na região central da Província Borborema (Figura 1). O arcabouço tectônico desta província foi inicialmente descrito como um conjunto de maciços e sistemas de dobramentos estruturados durante a Orogênese Brasiliana (Almeida et al. ,1977). Com a evolução dos conhecimentos, passou a ser apresentada como o resultado da ocorrência e superposição de mais de uma orogênese ao longo do tempo, e sua complexidade tectônica foi atribuída à aglutinação de terrenos alóctones de origens diferentes, separados por grandes zonas de cisalhamento (Jardim de Sá et al. 1992, Santos, 1996). Com o avanço no emprego das datações U-Pb em zircão e Sm-Nd em rocha total, as informações geocronológicas contribuíram de forma mais significativa para a separação da província em diferentes domínios tectônicos. Santos (1996) introduziu o modelo de terrenos tectonoestratigráficos, apoiando-se no conceito de terrenos alóctone, desenvolvido na Cordilheira Americana. Neste modelo, a Província Borborema foi formada pela aglutinação de grandes fragmentos de crostas (terrenos tectonoestratigráficos) durante as orogêneses Cariris Velhos (início do Neoproterozóico, em torno de 1,0 Ga) e Brasiliana (final do Neoproterozóico, em torno de 0,6 Ga).

A área de estudo está localizada na região de junção de três terrenos tectonestratigráficos propostos por Santos (2000): o Terreno Alto Moxotó (TAM) e o Terreno Rio Capibaribe (TRC), separados pela zona de cisalhamento Congo-Cruzeiro do Nordeste; e o Terreno PernambucoAlagoas, separado dos outros dois pela zona de cisalhamento de Pernambuco (Figura 1).

O Terreno Alto Moxotó, nesta área de estudo, possui um embasamento constituido por ortognaisses migmatíticos dioríticos-granodioríticos a tonalíticos, de idade paleoproterozóica, pertencentes ao Complexo Floresta. Ele está sobreposto pelas seqüências metavulcanossedimentares do Complexo Sertânia com idade em torno de $2.0 \mathrm{Ga}$. Ambos são intrudidos por rochas félsicas e máficas, também deformadas. Sobreposto a esse conjunto de rochas ocorre uma sequência metassedimentar de idade neoproterozóica (Accioly, 2009; Santos, 2009).

O Terreno Rio Capibaribe, nesta área de estudo, engloba complexos plutonometamórficos, seqüências metassedimentares e um intenso plutonismo neoproterozóico. Este terreno contém ainda ortognaisses e migmatitos indiscriminados e, metagranitóides peraluminosos, além da ocorrência volumosa de intrusões magmáticas neoproterozóicas, sin a tardibrasilianas, com afinidade geoquímica variada. O embasamento é representado pelo Complexo GnáissicoMigmatítico Pão de Açúcar, possivelmnete de idade paleoproterozóica (Accioly, 2009; Santos, 2009).

O Terreno Pernambuco-Alagoas, nesta área de estudo, é composto por gnaisses e xistos migmatizados com intercalações de quartzitos, além de rochas calciossilicáticas. Este complexo aloja corpos graníticos peraluminosos e migmatitos bandados com mesossoma de composição diorítica a tonalítica, e leucossoma 


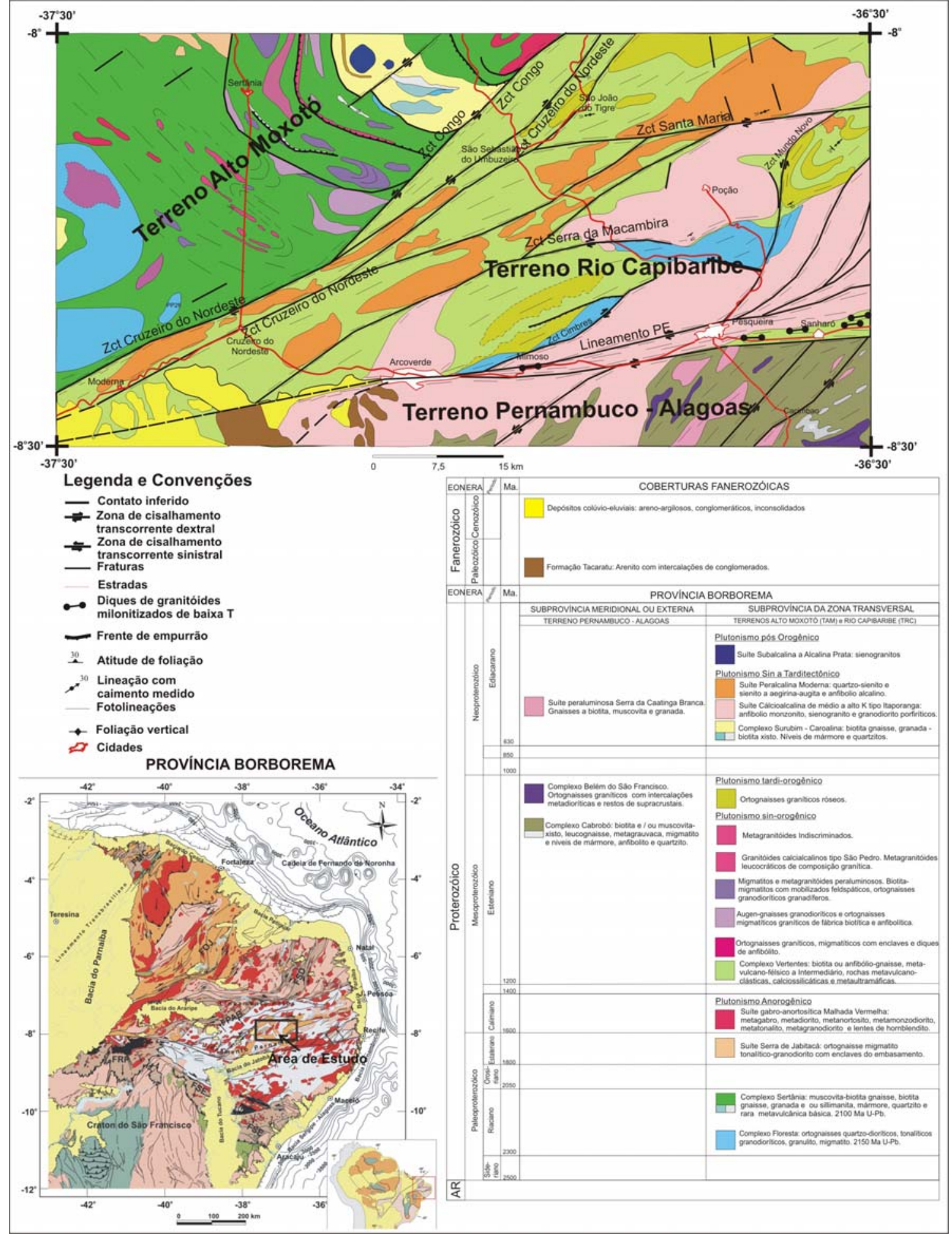

Figura 1: Aspectos geológicos da área de estudo e a sua localização no contexto da Província Borborema. A área é subdividida em três domínios geológicos que correspondem aos terrenos Alto Moxotó, Rio Capibaribe e Pernambuco Alagoas. 
sienogranítico. O plutonismo neoproterozóico é representado por um magmatismo peraluminoso, com presença em menor volume de magmatismo calcioalcalino (Accioly, 2009; Santos, 2009).

\section{Dados Geofísicos}

Os dados gravimétricos empregados fazem parte de um banco de dados formado a partir da junção de levantamentos efetuados em várias instituições de pesquisa para estudos regionais da Província Borborema (Oliveira, 2008). Os dados estão referenciados ao International Gravity Standardization Net -1971 (IGSN71). A anomalia Bouguer foi calculada para uma densidade da topografia igual a $2,67 \mathrm{~g} / \mathrm{cm}^{3}$. Para a interpretação e correlação geológica, os dados de toda a Província Borborema foram interpolados em uma malha de $10 \times 10$ $\mathrm{km}$, e em seguida foram processados para a remoção de comprimentos de onda de $300 \mathrm{~km}$ (Figura 2). Esse processamento permitiu a extração de uma componente residual que enfatiza as fontes com origem na crosta (Oliveira, 2008).

Neste trabalho foram empregados dados aerogeofísicos, magnetométricos e gamespectrométricos; e dados gravimétricos terrestres. Os dados aerogeofísicos foram levantados pelo Projeto Pernambuco-Paraíba-Rio Grande do Norte (Lasa \& Prospectors, 2010), contratado pela CPRM-Serviço Geológico do Brasil e realizado em consórcio pelas empresas Lasa Engenharia e Prospecções S.A. e Prospectors Aerolevantamentos e Sistemas Ltda. Foram efetuadas medidas do campo magnético terrestre total e da radioatividade natural das rochas com as linhas de vôo espaçadas de 500 metros na direção N-S, com a aeronave a 100 metros de altura do solo. Para a interpretação e correlação geológica, os dados foram interpolados em uma malha de 125 x $125 \mathrm{~m}$. No caso dos dados magnetométricos foram efetuadas filtragens para enfatizar as fontes rasas (sinal analítico, derivada vertical). Na Figura 3 está apresentada a imagem do campo magnético total. Para os dados gamaespectrométricos foi efetuada uma composição ternária com a junção dos canais de potássio, urânio e tório apresentada na Figura 4.

\section{Resultados}

Como será descrito abaixo, foram observados contrastes evidentes de densidade, magnetismo e radioatividade entre os três terrenos. A interpretação revelou que os dados magnetométricos, gamaespectrométricos e gravimétricos reforçam o modelo geológico de justaposição de crostas com propriedades petrofisicas diferentes, limitadas pelas zonas de cisalhamento CongoCruzeiro do Nordeste e Pernambuco.

O Terreno Alto Moxotó é gravimetricamente caracterizado por uma faixa de anomalia Bouguer residual positiva (Figura 2), com amplitude média de 12 $\mathrm{mGal}$ e direção geral NE-SW, que indica a existência de um grande volume de rochas com composição básica e/ou grau metamórfico alto. Essa faixa anômala é regionalmente correlacionada com ortognaisses migmatíticos dioríticos-granodioríticos a tonalíticos com idades paleoproterozóicas do Complexo Floresta. O maior gradiente da anomalia está correlacionado com a zona de cisalhamento Congo-Cruzeiro do Nordeste. A faixa de anomalias Bouguer positivas está espacialmente correlaciona com uma série de anomalias magnéticas alongadas na direção NW-SE (Figura 3). Estas anomalias estão truncadas e vergadas ao longo da zona de cisalhamento Congo-Cruzeiro do Nordeste. A principal correlação geológica dessas anomalias magnéticas é com ortognaisses paleoproterozóicos migmatizados, com enclaves e diques de anfibolito. As encaixantes dessas litologias são as rochas metavulcano-sedimentares do Complexo Sertânia. Nos dados gamaespectométricos, as rochas ortoderivadas apresentam um evidente enriquecimento em potássio (faixas avermelhadas na Figura 4), enquanto as rochas metavulcanosedimentares, com maior volume na superfície, estão levemente enriquecidas em tório e urânio (tons esverdeados e azulados, respectivamente na Figura 4). Os dados geofísicos indicam que o Complexo Floresta é caracterizado por assinaturas gravimétricas positivas, que sugere a existência de um grande volume de rochas densas, com empobrecimento em potássio, tório e urânio e um padrão magnético definido por eixos alongados na direção NE-SW. A assinatura geofísica do Complexo Sertânia é obscurecida pelo forte padrão apresentado pela intercalação de rochas magmáticas mesoproterozóicas, bem como, pelo sinal gravimétrico muito positivo apresentado pelo seu substrato. Este último fato revela que este complexo possui espessuras pequenas, possivelmente representando apenas um vestígio muito erodido de uma seqüência sedimentar originalmente mais espessa.

O Terreno Rio Capibaribe é gravimetricamente caracterizado por uma expressiva anomalia Bouguer negativa com amplitude média de $-22 \mathrm{mGal}$. Esta anomalia gravimétrica negativa está correlacionada com afloramentos de um volumoso plutonismo granítico regionalmente associado com o batólio de CaruaruArcoverde. Na região central da anomalia gravimétrica dominam rochas de composição calcialcalina com alto a médio potássio. A anomalia negativa forma um grande sigmóide, controlado a sul pela zona de cisalhamento Pernambuco, e a norte pela zona de cisalhamento Santa Maria. Neste terreno, as anomalias magnéticas são caracterizadas por estreitas faixas alongadas na direção NE-SW. Os dados magnéticos indicam que a crosta do Terreno Rio Capibaribe possui um volume muito menor de rochas magnéticas do que a crosta do Terreno Alto Moxotó. Os dados gamaespectrométrico indicam a dominância de rochas ácidas ricas em potássio (tons avermelhados na Figura 4), com a presença de faixas vestigiais de metassedimentos (tons esverdeados e azulados na Figura 4). As anomalias magnéticas, na maioria dos casos, estão associadas com zonas de cisalhamentos. Entretanto, observa-se também a correlação de anomalias magnéticas com rochas gabroanortosíticas (Suíte Malhada Vermelha). A assinatura gamaespectrométrica dessas rochas indica que elas são moderadamente enriquecidas em tório e urânio, porém empobrecidas em potássio. O enriquecimento em tório e urânio é claramente compreendido, por serem elementos 


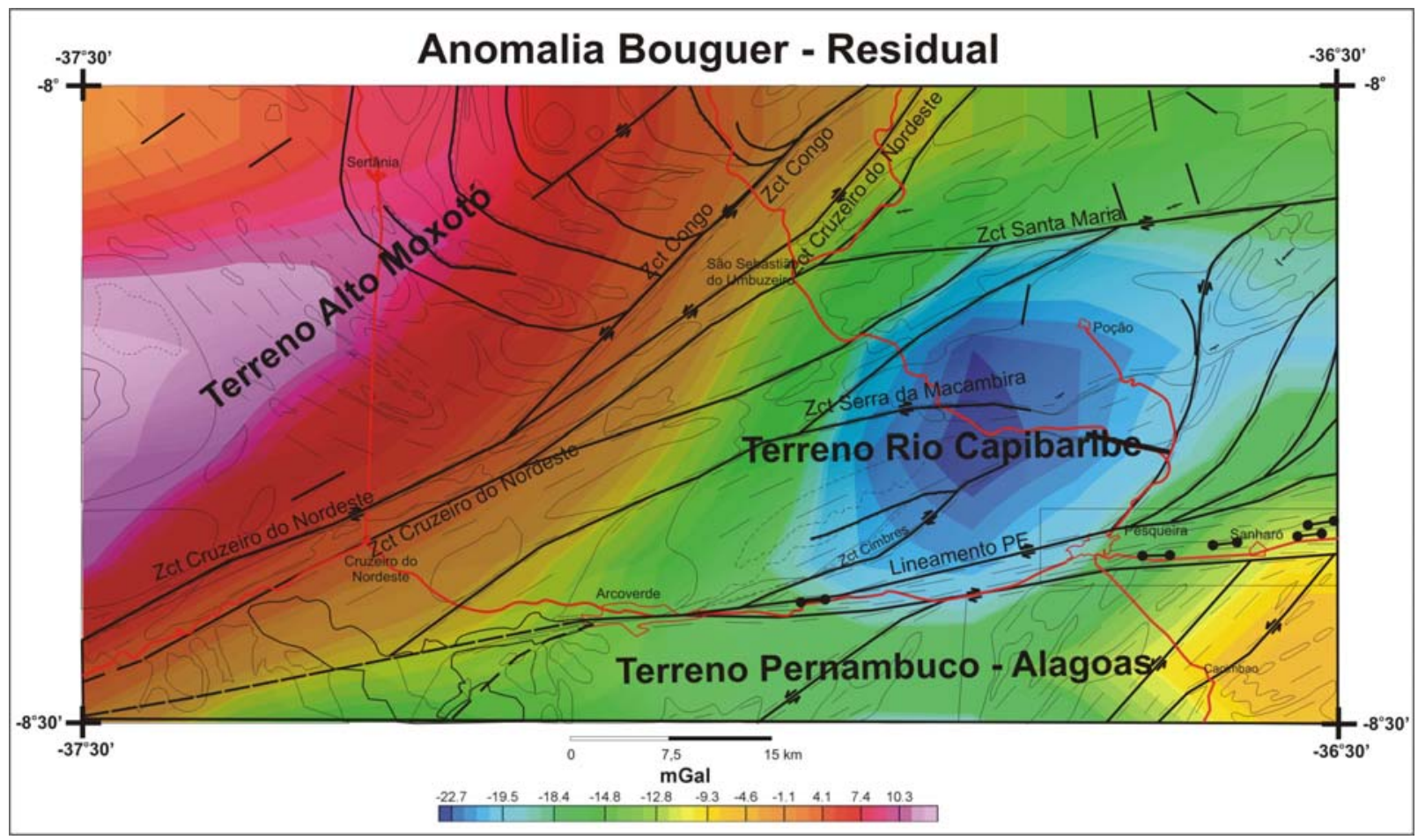

Figura 2: imagem da anomalia Bouguer residual com sobreposição dos contatos e estruturas geológicas. Grade de 10 x 10 km. Sombreada: inc.: $35^{\circ}$, dec.: $315^{\circ} \mathrm{Az}$.

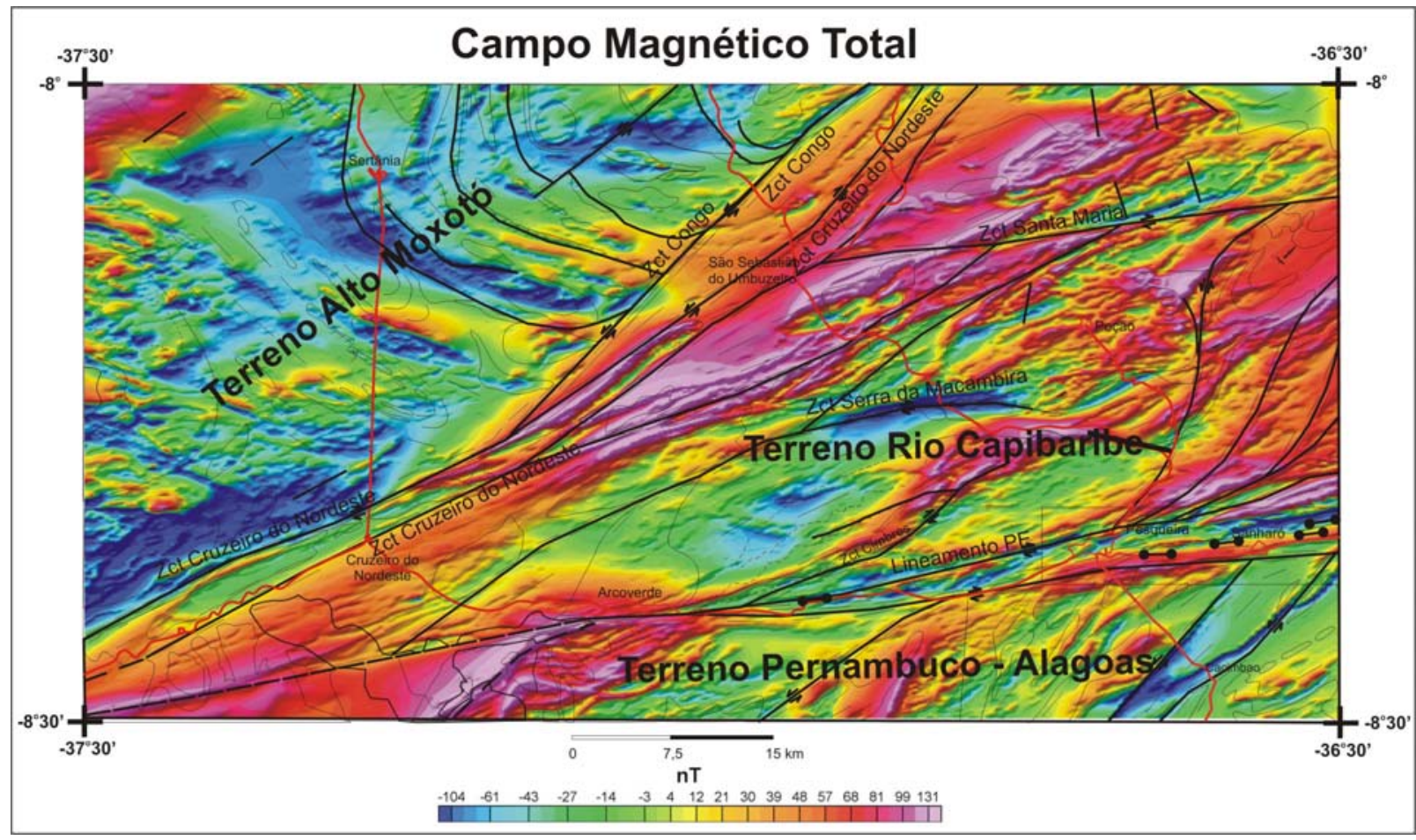

Figura 3: Imagem do Campo magnético total com sobreposição dos contatos e estruturas geológicas. Grade de 125 x 125 metros. Sombreada: inc.: $35^{\circ}$, dec.: $315^{\circ} \mathrm{Az}$. 


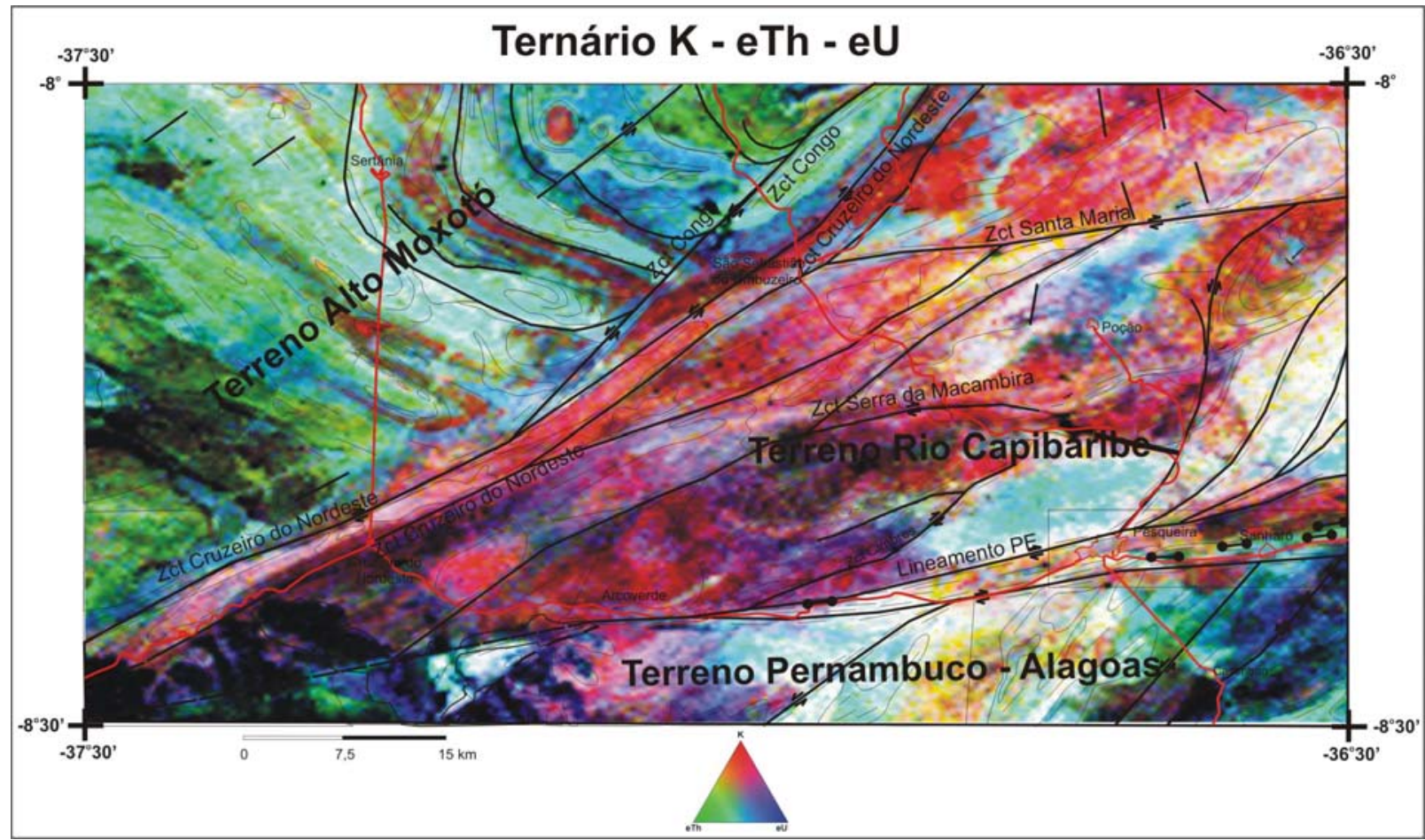

Figura 4: Imagem da composição radiométrica ternária K-eT-eU com sobreposição dos contatos e estruturas geológicas.

o tipo HFS (Hight Field Strenght Element), da mesma maneira que o titânio, elemento muito comum associado às suítes anortosíticas. O empobrecimento do potássio é também uma característica das rochas anortosíticas, onde o feldspato dominante é o plagioclásio. Ao longo da zona de cisalhamento Congo-Cruzeiro do Nordeste, o forte enriquecimento em potássio está correlacionado com alinhamentos de plútons da suíte intrusiva Vila Moderna, de natureza alcalina a peralcalina. Nos dados gamespectrométricos, a distribuição de potássio ocorre de forma homogênea, em clara concordância com a natureza peralcalina dessas rochas.

O Terreno Pernambuco-Alagoas, na área de estudo, não apresenta contrastes gravimétricos e radiométricos significativos em relação ao Terreno Rio Capibaribe, sobretudo por causa da influência do batólito granítico Caruaru-Arcoverde. Este batólito está alinhado segundo a zona de cisalhamento de Pernambuco e ocorre tanto a norte, como a sul desta estrutura $O$ contraste mais evidente ocorre nos dados magnéticos. Enquanto o Terreno Rio Capibaribe apresenta alinhamentos magnéticos com direção dominante NE-SW, no Terreno Pernambuco-Alagoas a direção principal é NNE-SSW. O limite de truncamento desses alinhamentos é a zona de cisalhamento Pernambuco, onde eles são vergados em uma tectônica dextral.

\section{Discussão e Conclusões}

Ao longo do Terreno Alto Moxotó, sobretudo nos seus flancos, ocorrem eclogitos retrometamorfisados (Beurlen \& Villaroel, 1990), cuja existência sugere que tenha ocorrido soerguimento de rochas ígneas máficas (basaltos ou gabros) que sofreram metamorfismo regional de alta pressão, possivelmente quando foram arrastados para o manto numa zona de subducção. Portanto, a existência dos retroeclogitos é um forte indício de colisão com subducção seguida por um grande soerguimento. $\mathrm{Na}$ análise dos dados gravimétricos, em um modelo de colisão, a zona de cisalhamento do Congo - Cruzeiro do Nordeste seria a candidata mais provável para delimitar uma zona de sutura. Do ponto de vista dos dados gravimétricos, se considerarmos em conjunto os terrenos Alto Moxotó e Rio Capibaribe, a assinatura gravimétrica ficaria definida por um par positivo-negativo com amplitude próxima de $40 \mathrm{mGal}$ e comprimento de onda em torno de $100 \mathrm{~km}$. Esses parâmetros sugerem a existência de uma importante descontinuidade crustal balizada pela zona de cisalhamento Congo - Cruzeiro do Nordeste. Em um contexto colisonal, o batólito CaruaruArcoverde poderia ser interpretado com um arco magmático continental.

Por outro lado a ausência de um contraste gravimétrico importante entre os terrenos Rio Capibaribe e Pernambuco - Alagoas dificulta sua interpretação como uma estrutura que assinala uma descontinuidade importante na crosta. No entanto, do ponto de vista dos 
dados geofísicos, o Terreno Rio Capibaribe não se encaixa regionalmente no padrão característico do Terreno Pernambuco - Alagoas. Ele possui regionalmente um sinal gravimétrico dominantemente negativo e uma crosta menos magnética do que a crosta do Terreno Pernambuco - Alagoas. Além disto, este terreno possui uma estruturação gravimétrica regional, definida por alternância de faixas gravimétricas positivas e negativas com direção NE-SW (Oliveira, 2008).

Com base nos dados apresentados, é possível concluir que os aspectos geofísicos mais relevantes são:

i) o emparelhamento da anomalia gravimétrica negativa do Terreno Rio Capibaribe com a anomalia gravimétrica positiva do Terreno Alto Moxotó, em que o positivo tem uma clara correlação com as rochas paleoproterozóicas do Complexo Floresta, e o negativo possui também uma clara correlação com as rochas do batólito CaruaruArcoverde;

ii) os dados gravimétricos permitem interpretar que o Complexo Floresta é o principal substrato para as supracrustais do Complexo Sertânia;

iii) os dados geofísicos indicam que o Complexo Sertânia possui espessuras pequenas, talvez, representando um vestígio muito erodido de uma seqüência sedimentar mais espessa;

iv) o forte contraste magnético entre os terrenos Rio Capibaribe e Alto Moxotó, tanto quanto a intensidade da magnetização, como quanto à direção dos alinhamentos magnéticos;

v) o contraste radiométrico entre os terrenos Rio Capibaribe e Alto Moxotó. O primeiro com uma assinatura típica de rochas graníticas ácidas e o segundo com uma assinatura típica de metassedimentos e rochas de embasamento ortoderivado; e

vi) o contraste magnético entre os terrenos Rio Capibaribe e Pernambuco - Alagoas, sobretudo quanto à direção dos alinhamentos magnéticos;

\section{Agradecimentos}

CPRM - Serviço Geológico do Brasil.

\section{Referências}

Accioly A.C.A. 2010. Pesqueira. Folha SC.24-X-B-II. Estados de Pernambuco e Paraíba. Escala 1:100.000. Geologia e Metalogênese. Recife: CPRM, 1 CD-ROM. (no prelo).

Almeida F.F.M., Hasui Y., Brito Neves B.B. \& Fuck H.A. 1977. Províncias Estruturais Brasileiras. In: SBGNúcleo Nordeste, Simpósio de Geologia do Nordeste, $8^{\underline{0}}$, Campina Grande, Atas, Boletim 6, p. 363-391.

Beurlen H. \& Villaroel H.S. 1990. Petrografia de duas ocorrências de provável eclogito em Bodocó e Floresta no Estado de Pernambuco, Brasil. Revista Brasileira de Geociências, 20:111-121.

Jardim de Sá E.F., Fuck R.A., Macedo M.H.F. \& Kawashita K. 1992. Terrenos Proterozóicos na Província
Borborema e a margem Norte do Cráton São Francisco. Revista Brasileira de Geociências, 22(4):472-480.

Lasa \& Prospectors 2010. Projeto Aerogeofísico Paraíba - Rio Grande do Norte e Pernambuco - Paraíba. Relatório Final. Rep. Fed. do Brasil, MME-CPRM.

Oliveira R.G. 2008. Arcabouço Geofísico, Isostasia e Causas do Magmatismo Cenozóico da Província Borborema e de Sua Margem Continental (Nordeste do Brasil). Tese de Doutorado, PPGG/CCET/UFRN, Natal, 411p.

Santos C.A. 2010. Sertânia, Folha SC.24-X-B-I. Estados de Pernambuco e Paraíba. Escala 1:100.000. Geologia e Metalogênese. Recife: CPRM, 1 CD-ROM. (no prelo).

Santos E.J. 1996. Ensaio preliminar sobre terrenos e tectônica acrescionária na Província Borborema. In: SBG, Congresso Brasileiro de Geologia, 39ํㅡㄴ, Salvador, Anais, 6:47-50.

Santos E.J. 2000. Contexto Tectônico Regional. In: Medeiros V.C. 2000 (Org.). Programa Levantamentos Geológicos Básicos do Brasil. Folha Aracaju/NE - SC.24$X$ (escala 1:500.000). Brasília, CPRM, p.3-7. 